\title{
PIK3CA NP_006209.2:p.E545K
}

National Cancer Institute

\section{Source}

National Cancer Institute. PIK3CA NP 006209.2:p.E545K. NCI Thesaurus. Code C98468.

A change in the amino acid residue at position 545 in the phosphatidylinositol-4,5-

bisphosphate 3-kinase catalytic subunit alpha isoform protein where glutamic acid has been replaced by lysine. 